\title{
Prescribing Pattern in Outpatient Departments of Two Tertiary Care Teaching Hospitals in Dhaka
}

\author{
Halima Begum ${ }^{1}$, Mahfuza Mazeda Rowshan ${ }^{2}$, Sayeda Khanom ${ }^{3}$, Shammin Haque ${ }^{4}$, \\ Farhana Afroze ${ }^{5}$, Ashrafun Naher Dina ${ }^{6}$ \\ Received: April 8, 2015 Accepted: July 9, 2015 \\ doi: http://dx.doi.org/10.3329/jemc.v5i3.24747
}

\begin{abstract}
Background: Medically inappropriate, ineffective and economically inefficient use of drugs is very common in our country. About $40 \%$ or more drugs expenditure may be wasted through irrational prescribing and dispensing. The need for promoting rational use of drugs is not only because of economic considerations; also it is an essential element for achieving quality of the health and medical care for patients and the community. For this purpose a cross sectional study was carried out among the individuals attending the outpatient departments (OPD) of Medicine, Surgery, Gynecology \& Obstetrics, Pediatrics, Orthopedics, Dermatology \& Venereology, Ophthalmology and Otolaryngology of two tertiary care teaching hospitals of Dhaka, Bangladesh. Objective: To observe the prescribing pattern in outpatient departments of two tertiary care teaching hospitals (Dhaka) by using World Health Organization (WHO) core prescribing indicators. Materials and Methods: Six hundred prescriptions of patients attending the OPD of Medicine, Surgery, Gynecology \& Obstetrics, Pediatrics, Orthopedics, Dermatology \& Venereology, Ophthalmology and Otolaryngology of Enam Medical College Hospital (private hospital) and Sir Salimullah Medical College Hospital (public hospital) were collected randomly on working days from April to September 2014. Then the prescriptions were analyzed by following the "Prescribing indicators form" as recommended by the International Organization of Rational Use of Drugs (INRUD)/WHO. Results: Average number of drugs per prescription was significantly high (3.07 in public hospital and 3.00 in private hospital). Generic prescribing was significantly lower in private hospital (4.00\%) than that in public hospital (21.00\%). Antibiotic prescription was higher in private hospital (42.35\%). Injection prescribed in public hospital was $5.74 \%$ whereas $5.66 \%$ in private hospital. Drugs prescribed from Essential Drug List of Bangladesh were less in both the hospitals $(42.85 \%$ in public hospital and $40.06 \%$ in private hospital). Conclusion: Average number of drugs per prescription was higher in both hospitals. Generic prescribing was lower in private hospital and prescribing from EDL was low in both hospitals.
\end{abstract}

Key words: Public hospital; Private hospital; Generic prescribing

J Enam Med Col 2015; 5(3): 157-160

\section{Introduction}

World Health Organization (WHO) convened a major conference in 1985 in Nairobi regarding rational use of drugs. Since then efforts have increased to improve drug use practices. An essential tool for such work is an objective method to measure drug use in health facilities that will describe drug use pattern and

1. Assistant Professor, Department of Pharmacology \& Therapeutics, Enam Medical College, Savar, Dhaka 2. Assistant Professor, Department of Pharmacology \&Therapeutics, Sir Salimullah Medical College, Dhaka 3. Assistant Professor, Department of Pharmacology \& Therapeutics, Central International Medical College, Dhaka 4. Assistant Professor, Department of Pharmacology \& Therapeutics, Dr. Sirajul Islam Medical College, Dhaka 5. Assistant Professor, Department of Pharmacology \& Therapeutics, Shaheed Mansur Ali Medical College, Uttara, Dhaka 6. Assistant Professor, Department of Pharmacology \& Therapeutics, Enam Medical College, Savar, Dhaka Correspondence Halima Begum, Email: halimadnmc@yahoo.com 
prescribing behavior. Drugs play an important role in protecting, maintaining and restoring health. Prescription writing is a science and art as it conveys the message from the prescriber to the patient. The treatment of disease by the use of essential drugs, prescribed by their generic names, has been emphasized by WHO. ${ }^{1,2}$

Almost half of all medicines globally are used irrationally. Medicine experts in WHO say, irrationality can have severe consequences: adverse drug reactions, drug resistance, protracted illness and even death. In addition, the financial cost incurred by individuals and governments due to irrational use is unnecessary and often extremely high, particularly in developing countries where patients often pay for medicines out of pocket. Irrational use of medicines includes overtreatment of a mild illness, inadequate treatment of a serious illness, misuse of anti-infective drugs, over-use of injections, self-medication of prescription drugs and premature interruption of treatment. Data from many countries show that such practices are frequent, and not exclusive to developing countries. ${ }^{3}$

The assessment of drug utilization is important for clinical, educational and economic purposes. ${ }^{4}$ Prescribing patterns need to be evaluated periodically to increase the therapeutic efficacy, decrease adverse effects and provide feedback to prescribers. 5,6 Therefore, the present study has been undertaken to analyze the prescribing pattern of drug use in outpatient department (OPD) and to offer feedback to drug prescribers for improving the prescription pattern for the benefit of the patients.

\section{Materials and Methods}

This cross sectional study was carried out in the Department of Pharmacology and Therapeutics of two tertiary care teaching hospitals of Dhaka during the period April 2014 to September 2014 (6 months). One hospital was from the public sector, Sir Salimullah Medical College Hospital (SSMCH) and the other was from the private sector, Enam Medical College Hospital (EMCH). Six hundred prescriptions were collected from the outpatient department (OPD) of different disciplines (Medicine, Surgery, Gynecology \& Obstetrics, Pediatrics, Orthopedics, Dermatology \& Venereology, Ophthalmology and Otolaryngology).
Prescriptions were randomly collected from OPD after taking the informed consent from all patients. Patients visiting the emergency department or who got admitted during OPD visit were not included in the study.

The data were analyzed by using "Prescribing Indicators form" which was recommended by the INRUD/WHO. WHO Prescribing Indicators are as follows:

- Average number of drugs per encounter

- Percentage of drugs prescribed by generic name

- Percentage of encounters with an antibiotic prescribed

- Percentage of encounters with an injection prescribed

- Percentage of drugs prescribed from essential drug list or formulary

The data were entered and analyzed by using SPSS version 12.0. Results were computed separately for each of the two hospitals included in the study. Two sample t-test was employed to detect any significant difference between the public and private hospitals prescribing pattern.

\section{Results}

A total of 1802 individual drugs were prescribed in 600 prescriptions. Average number of drugs per prescription was 3.07 in public hospital and 3.00 in private hospital. The proportion of drugs per prescription showed no significant $(\mathrm{p}>0.05)$ difference between two hospitals.

Prescribing systemic agents in generic names was very low $(4 \%)$ in private hospital than that in public hospital $(21 \%)$. There was significant difference in using generic names in prescription $(\mathrm{p}=0.0423)$ between two hospitals. In the public hospital percentage of encounters with antibiotics was $24.00 \%$ whereas in the private hospital it was $49.3 \%$; there was significant difference between two hospitals $(\mathrm{p}<0.001)$. Injection prescribed in public hospital was $5.74 \%$ whereas in the private hospital it was $5.66 \%$; there was no significant difference in pattern of injection use $(\mathrm{p}>0.05)$. In public hospital only $42.85 \%$ and in private hospital $40.06 \%$ drugs were prescribed from essential drug list (EDL) with no significant difference between two hospitals $(\mathrm{p}>0.05)$. 
Table I: Prescription pattern in the study hospitals

\begin{tabular}{|l|c|c|c|}
\hline WHO core prescribing indicators & Public hospital & Private hospital & p values \\
\hline Average number of drugs per & $3.07 \pm 1.85$ & $3.00 \pm 1.82$ & $>0.05$ \\
\hline encounter $( \pm$ SD) & $(922$ in 300) & $(901$ in 300) & \\
\hline Percentage of drugs prescribed by generic names & $21.00 \%$ & $4.00 \%$ & 0.0423 \\
\hline Percentage of encounters with an antibiotic prescribed & $24.00 \%$ & $49.35 \%$ & $<0.0001$ \\
\hline Percentage of encounters with an injection prescribed & $5.74 \%$ & $5.66 \%$ & $>0.05$ \\
\hline Percentage of drugs prescribed from essential drug list & $42.85 \%$ & $40.06 \%$ & $>0.05$ \\
\hline
\end{tabular}

\section{Discussion}

Any drug utilization study based on the WHO core drug use indicators has limitations. ${ }^{2}$ Determining the quality of diagnosis and evaluating the adequacy of drug choices are beyond the scope of the prescribing indicators. ${ }^{2}$ Also, the patient care indicators do not capture many fundamental issues related to the quality of examination and treatment ${ }^{2}$, and it was not done in present study. In this study, it seems that prescribers at the public health care center followed the standard guidelines more than private health care center prescribers. It may be because of less secure and temporary nature of job in the private sector where the work is regularly monitored which is often linked to patient satisfaction. There are features of deviation from rational prescribing regarding average number of drugs per prescription which was significantly high in both hospitals; generic prescribing was very low in private hospital; antibiotic prescription was higher in private hospital and less number of drugs prescribed from EDL in both hospitals.

It has been recommended that the limit of number of drugs prescribed per prescription should be two and justification for prescribing more than two drugs would be required because of increased risk of drug interactions. ${ }^{7}$ In this study the incidence of polypharmacy has found in both hospitals. Average number of drugs per prescription was 3.07 in public hospital whereas in private hospital it was 3.00. The result was similar with the study result of Bangladesh (3.22) and Nigeria (3.3). ${ }^{8,9}$

The trend of polypharmacy may be due to the patient's expectations and demand of quick relief, the incorrect diagnosis and the influence of the lucrative promotional programs of the drug companies. ${ }^{4}$ Polypharmacy is known to cause unnecessary adverse reactions, drug interactions, unnecessary drug expenses and complications.

In the present study generic prescribing was dominated in both hospitals and more in private hospitals. Only $4 \%$ drugs in private hospital and $21 \%$ drugs in public hospital were prescribed by generic names. Public hospital results are similar to findings in Nepal $(21.3 \%)^{10}$, and private hospital results are nearly similar to the results of Dubai $(4.4 \%) .{ }^{11}$ But the results of both hospitals were very much lower than that reported in studies conducted in Cambodia $(99.8 \%)^{12}$, Zimbabwe $(94 \%)^{13}$ and Sudan $(63 \%)^{9}$. The higher rate of generic prescribing in public hospital may be due to availability of generic formulations whereas in private hospital use of generic names is low due to doubt about efficacy and bioavailability of generic formulations and lack of information on availability of generic formulation from pharmaceutical companies. ${ }^{1}$

The percentage of encounters with an antibiotic prescribed was $49.35 \%$ in private hospital whereas in public hospital it was $24.00 \%$. The practice of antibiotic drug use in public hospital was better compared to that of private hospital. It is nearly similar to the results of Bangladesh (25\%), Ecuador (27\%) and Zimbabwe (29\%). ${ }^{9}$ Percentage of encounters with an antibiotic prescribed is high in private sector and it was nearly similar to the findings of Bangladesh $(48.67 \%)^{8}$ and Norway $(48 \%)^{14}$. High antibiotic prescribed in private hospital could be due to defensive prescribing, pressure from patients and relatives, inadequate knowledge of proper indications. ${ }^{15}$ 
WHO recommended target for injection use per encounter is $10 \%$ or less. ${ }^{2}$ Percentage of encounters with an injection prescribed in both public $(5.66 \%)$ and private $(5.74 \%)$ hospitals was within recommended limit of $\mathrm{WHO}$ and there was no significant difference $(p>0.05)$ regarding injection use pattern in these two hospitals. Findings are nearly similar to findings of Nepal $(5 \%) .{ }^{9}$ However, rates are high in Uganda $(48 \%)^{16}$ and Nigeria $(37 \%)^{9}$ compared to current study.

About $42.85 \%$ (in public hospital) and $40.06 \%$ drugs (in private hospital) were prescribed from national EDL. It is remarkably less than that reported in India. In a review article Biswas et al have shown that $74.1 \%-95.8 \%$ of prescribed drugs are from national EDL. ${ }^{17}$ In another study Karande et al have found that $90.3 \%$ drugs are from EDL. ${ }^{18}$

The percentage of drugs prescribed from the EDL seems to be not close to the desired standard. ${ }^{2}$ It may be due to undersupply of essential drugs or oversupply of non-essential pharmaceutical products. A locally adapted EDL will help promote rational drug use in our outpatient departments. ${ }^{2}$

Healthcare providers play major role in rational use of drugs (RUD) activities and have a professional liability to improve prescribing practice and the quality of patient care. Therefore, the present study may provide them feedback on concept of Essential Drugs and Rational Use of Drug to improve prescribing pattern. Interventions are needed to rectify polypharmacy, overprescription of antibiotics and lack of access to an essential drugs list for further improvement of appropriate drug use in our outpatient departments.

\section{References}

1. Kumar MA, Noushad PP, Shailaja K, Jayasutha J, Ramasamy C. A study on drug prescribing pattern and use of corticosteroids in dermatological conditions at a tertiary care teaching hospital. International $\mathrm{J}$ of Pharmaceutical Sciences Review and Research 2011; 9(2): 132-135.

2. World Health Organization (WHO). International Network for Rational Use of Drugs and World Health Organization. How to investigate drug use in health facilities-selective drug use indicators, Geneva. WHO Department of Essential Drug and Medicine Policy 1993: 1-87. EDM Research Series No. 7 [WHO/DAP/93.1].
3. World Health Organization Media Centre. Promoting rational use of medicines saves lives and money, WHO experts say. Available at: http://www.who.int/mediacentre/news/ notes/2004/ np9/en/. Accessed November 2014.

4. Uppal R, Nayak P, Sharma PL. Prescribing trends in internal medicine. Int J Clin Pharm Therapy and Toxicol 1984; 22(7): 375-376.

5. Krishnaswamy K, Kumar BD, Radhaiah G. A drug use surveyprecepts and practices. Eur J Clin Pharmacol 1985; 29: 363-370.

6. Pradhan SC, Shewade DG, Shashindran CH, Bapna JS. Drug utilization studies. National Med J India 1988; 1: 185-189.

7. Nies SA. Principles of therapeutics. In: Gilman GA, Rail WT (eds). The pharmacological basis of therapeutics. New York: Pergman Press, 1990: 62-83.

8. Afsan A, Alam MM, Noor N, Ahmed AHH. Prescribing practices in the outpatient department in a tertiary care teaching hospital in Bangladesh. Update Dental College J 2012; 2(2): 13-17.

9. Hogerzeil HV, Bimo, Ross-Degnam D, Laing RO, Ofori-Adjei D, Santoso B et al. Field tests for rational drug use in twelve developing countries. Lancet 1993; 342: 1408-1410.

10. Shankar RP, Pranab KS, Upadhyay DK, Dubey AK, Subish P. Drug utilization among surgical outpatients. TMJ 2006; 56(2-3): 230-234.

11. Sharif SI, Al-Shaqra M, Hajjar H, Shamout A, Wess L. Patterns of drug prescribing in a hospital in Dubai, United Arab Emirates. Libyan J Med 2008; 3(1): 10-12.

12. Chareonkul C, Khun VL, Boonshuyar C. Rational drug use in Combodia: study of three pilot health centers in Kampong Thom Province. Southeast Asian J Trop Med Public Health 2002; 33: 418-424.

13. Lessing C, Trap B. Zimbabwe Essential Drugs Action Programme (ZEDAP) 1995. Ministry of Health and Child Welfare Directorate of Pharmacy.

14. Lindbaek M, Berild D, Straand J, Hjordahl P. Influence of prescription pattern in general practice on antimicrobial resistance in Norway. Brit J Gen Pact 1999; 49: 436-440.

15. Amane H, Kop P. Prescription analysis to evaluate rational use of antimicrobials. International $\mathrm{J}$ of Pharma and Bio Sciences 2011; 2(2): 314-319.

16. Sarah D, Kasewa GW, Pariyo O, Okui O, Kabagamb G, White M. Evaluation of drug use practices in government health units. J Clin Epidemol 1997; 50: 44S.

17. Biswas NR, Biswas RS, Pal PS, Jain SK, Malhotra SP, Gupta A et al. Patterns of prescriptions and drug use in two tertiary hospitals in Delhi. Indian J Physiol Pharmacol 2000; 44: 109-112.

18. Karande S, Sankhe P, Kulkarni M. Patterns of prescription and drug dispensing. Indian J of Pediatrics 2005; 72: 117-121. 